\title{
SISTEMA MITOCONDRIAL ANIMAL (SISMIT): UN PROGRAMA DE COMPUTACIÓN APLICADO EN EL ANÁLISIS MOLECULAR DE LOS GENOMAS MITOCONDRIALES DE ANIMALES VERTEBRADOS
}

\section{SISTEMA MITOCONDRIAL ANIMAL (SISMIT): A COMPUTING SOFTWARE BASED IN THE MOLECULAR ANALYSIS OF MITOCHONDRIAL GENOMES OF VERTEBRATES}

\author{
C. Scotto' y R. Valdivia ${ }^{2}$
}

\section{RESUMEN}

El presente trabajo reporta el diseño de un programa de computación que analiza a nivel molecular las secuencias del DNA mitocondrial de 37 animales vertebrados domésticos y silvestres de importancia zoogenética.

Palabras clave: DNA mitocondrial, Programa de Computación, RFLP, PCR

\section{ABSTRACT}

The present article reports the design of a computing program which analizes at the molecular level the sequences of mitochondrial DNA (mtDNA) of 37 domestic and wild life vertebrates of zoogenetic importance.

Key words: mitochondrial DNA (mtDNA), Computer Program, RFLP, PCR.

\section{INTRODUCCIÓN}

Los avances tanto en el campo de la biología molecular como en la informática han permitido el desarrollo de una nueva área de la ciencia denominada bioinformática.

En 1979, BROWN et al. predijeron que las moléculas de DNA mitocondrial de los vertebrados (mtDNA) Ilegarían a ser una de las primeras moléculas de DNA en ser totalmente secuenciadas con el tiempo, debido a que son las unidades genómicas eucarióticas

\footnotetext{
1 Laboratorio de Bioquimica y Biologia Molecular. Universıdad Nacional Fe. derico Villarreal. Lima. Peru.

E-mail:scotoc@hotmall.com

2 Instieuto Nacional de Recursos Naturales. INRENA. Lima.Perú.
}

más simples que existen en la naturaleza, pues tienen un tamaño promedio de 16500 nucleótidos (Rosamond, 1982) y carecen de intrones (Anderson et al., 1981).

Abreviaturas: $\mathrm{PCR}=$ Polymerase Chain Reaction; RFLP = Restriction Fragment Length Polymorphisms; $b p=$ base pairs.

Es así que durante los últimos veinte años se han estado reportando las secuencias nucleotídicas completas del DNA mitocondrial de diferentes animales vertebrados disponibles actualmente en el Genbank ( 1999) de Internet.

Por otro lado, debido a las características que esta molécula posee es muy utilizada en 
diferentes estudios a nivel molecular para la construcción de mapas de restricción por RFLP (NEI, et al., 1979; Brown, 1980) o para la amplificación de segmentos específicos por PCR (Higuchi et al., 1984). El patrón electroforético de bandas obtenido en un gel por RFLP o PCR, junto con el patrón de bandas de un marcador comercial, en cualquier laboratorio son analizados a simple vista o con la ayuda de lectores ópticos para su detección (Scott et al., 1993).

Hoy, existen programas de computación que son bancos de datos de secuencias nucleotídicas como el Genbank (Altschul et al., 1990) y de secuencias de aminoácidos como el Proteindata Bank (Bernstein et al., 1977). Otros programas de computación trabajan con estas secuencias haciendo predicciones, comparaciones por homología y análisis de sus propiedades intrínsecas como son el Blastp, Seqaid, Oligo, Macaw, etc., (Karlin \& Altschul, 1990). Sin embargo, ningún programa integra tanto la información molecular dentro de una base de datos junto con las secuencias nucleotídicas o de aminoácidos y las principales técnicas moleculares utilizados en el análisis de genomas mitocondriales como son el RFLP y el PCR.

En respuesta a este problema, se desarrolló y patentó el programa de computación Sismit
Animal, Versión 1.0 (1999). Este programa constituye el primer programa de biología molecular aplicado en el análisis del mtDNA de animales vertebrados utilizando un sistema visual de análisis de imágenes digitales por computadora.

\section{MATERIALES Y MéTODOS}

El Sismit Animal (1999) fue creado utilizándose el programa Pascal, versión 7.0 (Tenenbaum \& Augenstein, 1981) y la información del trabajo de Tesis de Scotto (1996).

\section{RESULTADOS}

El Sismit Animal fue diseñado de forma versátil para funcionar en computadoras desde el modelo AT-286 con 1 Megabyte de Memoria RAM y en cualquier tipo de pantalla monocromática o a color.

El programa utiliza algoritmos matemáticos apropiados para proyectar una pantalla de Menú Principal (Fig. 1) y varias pantallas para los Submenús que contienen diferentes opciones seleccionables por el usuario (Fig. 2).

Dentro del Menú Principal las opciones Datos Básicos y Diccionario son bancos de datos con información mitocondrial actualiza-

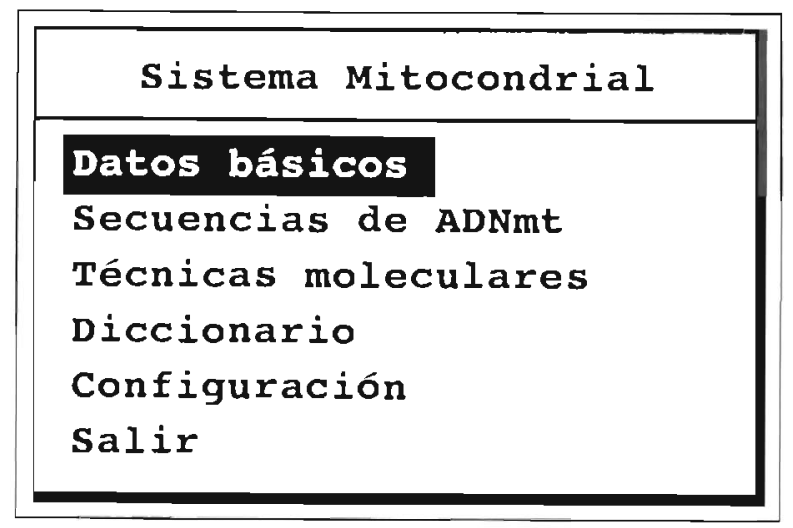

Figura 1. 1) Datos básicos; 2) Secuencias de DNAmt; 3) Técnicas moleculares; 4) Diccionario; 5) Configuración; 6) Salir 


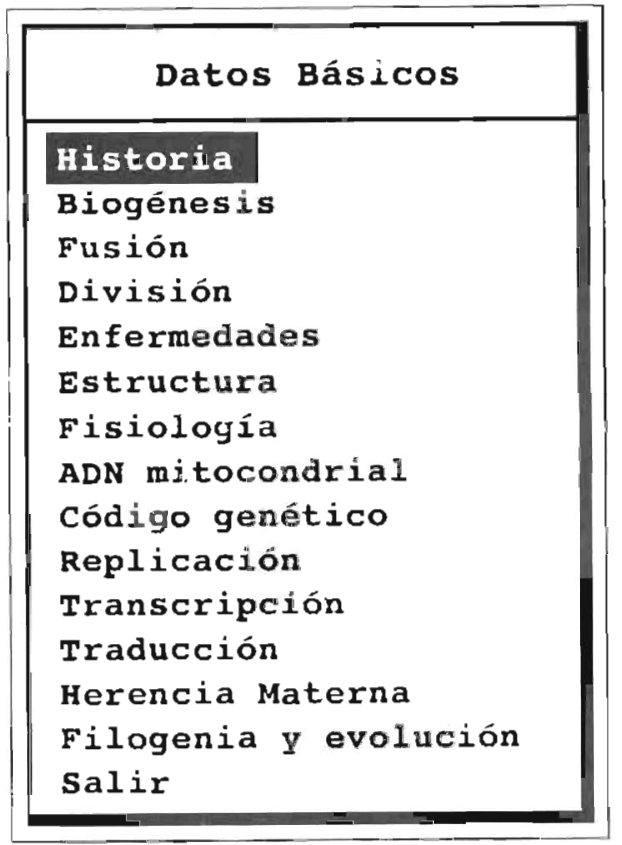

Figura 2. 1) Historia; 2) Biogénesis; 3) Fusión; 4) División; 5) Enfermedades; 6) Estructura; 7) Fisiologia; 8) ADN mitocondrial; 9) Código genético; 10) Replicación; 11) Transcripción; 12) Traducción; 13) Herencia Materna; 14) Filogenia y evolución; 15) salir.

da (Fig. 3), los cuales están complementados con la proyección de gráficos descriptivos para cada tema seleccionado (Fig. 4).
La opción Secuencias del DNA mitocondrial permite seleccionar el miDNA de uno de los 37 animales vertebrados dife-

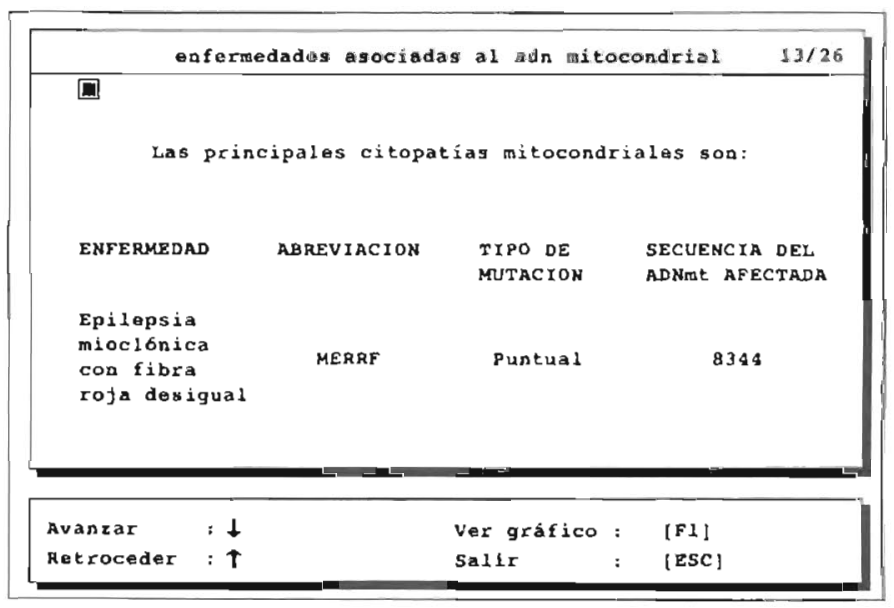

Figura 3. Se describe una citopatía mitocondrial denominada Epilepsia mioclónica con fibra roja desigual. Su abreviación: MERRF. Tipo de mutación: Puntual. Secuencia del mtDNA alectada: 8344 


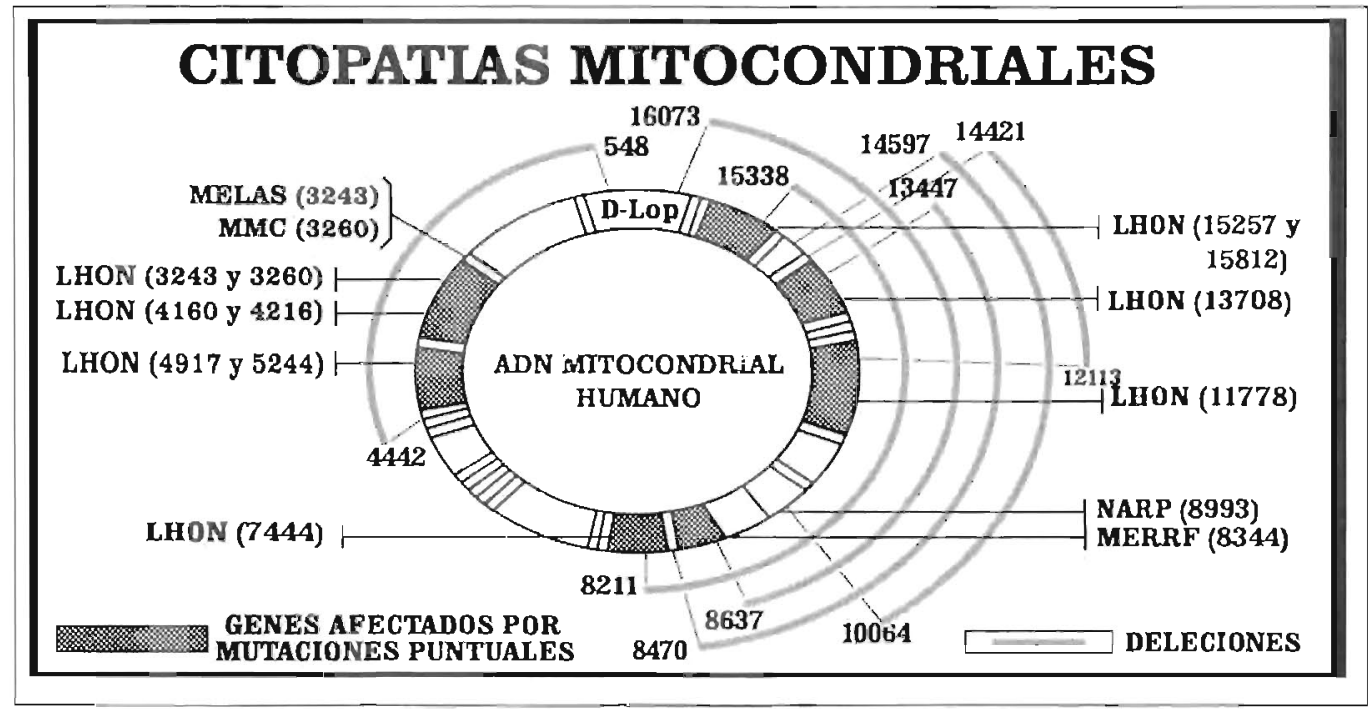

Figura 4. Se describe las regiones en la molécula del mtDNA donde se han identificado las principales mutaciones de tipo puntual (números) o por deleción (semicírculos) que producen enfermedades en humanos con las abreviaciones: LHON, MEL AS MERRF, MMC y NARP.

rentes con que trabaja el programa (Fig. 5). Además, para cada cadcria del miDNA seleccionada (Cadena H o L) puede obtenerse información de cada uno de los 37 genes que poseen las moléculas de miDNA de los vertebrados: 22 RNA mensajeros, 2 RNA ribosómicos y 1.3 genes para proteínas (CANN et al., 1987) como son la secuencia del gen seleccionado, los porcenlajes de bases nitrogenadas (adenina, guanina, citosina y limina) y el número de nuclétidos totales del gen seleccionado (Fig. 6).

Dentro de cata opción y al suleccionarse un gen que codifique para una proteína se obtendrá su secuencia de aminoácidos respecti-

\begin{tabular}{|c|c|c|c|}
\hline \multicolumn{4}{|c|}{ Secuencia de ADN mitocondrial } \\
\hline Asno & (Eqgus asinus) & Hunano 2 & (Homo sapiens) \\
\hline Bacalao & (Gadus worhus) & รumano 3 & (Homo sapiens) \\
\hline Ballena aleta & (Balaenoptera phybalis) & Eumano 4 & (Bomo sapiens) \\
\hline Ballane axul & (Balaopoptera mugculus) & Bumano 5 & (Homo sapiens) \\
\hline Bovino & (Bos taurue) & Iampraa & (Petronyzon marinus) \\
\hline Cabal1o & (Eqqua caballug) & Orangutan 1 & (Pongo pygmaeus pygmaeus) \\
\hline Canguro & (Macropus robustus) & Orangutan 2 & (Pongo pygmaeus abelit) \\
\hline Carpa & (Cyprinua carpio) & ornitorrinco & (Ornithorrhyachus anatinus) \\
\hline Celacanto & (Latimeria chalumaa) & Pez africano & (Polypterus ortanipiania) \\
\hline Cblmpance 1 & (Pan trogloōytes) & Pez asiático & (Crassostana lacustra) \\
\hline Chimpance 2 & (Pan troglodytes) & Pcz pulmonado & (Protopterus Colloi) \\
\hline $\operatorname{Er} 120$ & (Erinaceus europaeus) & Po110 & (Gallus gallus) \\
\hline FECL 1 & (Ealichoerus grypbus) & Roga de garres & (Xenopus laevis) \\
\hline Foca 2 & (Phoca vituliaa) & Rata & (Rattus norvegicus) \\
\hline Gato & (Felis catus) & Ratión & (Mus xusculus) \\
\hline aibon & (Bylobates lax) & Binocaronte & (Whinocerus unicornis) \\
\hline Gorila 1 & (Gorilla gorilla) & Trucha & (Oncorbynchus mykiss) \\
\hline aorila 2 & (Gorilla gorilla) & zarlgueya & (Didelophis virginiana) \\
\hline $\begin{array}{l}\text { Bumano } 1 \\
\text { Salix }\end{array}$ & (Homo anpiens) & Compazacleses & \\
\hline
\end{tabular}

Figura 5. I a pantalla muestra las 37 especies diferentes de vertebrados cuyo DNA mitocondrial está en la base de datos 


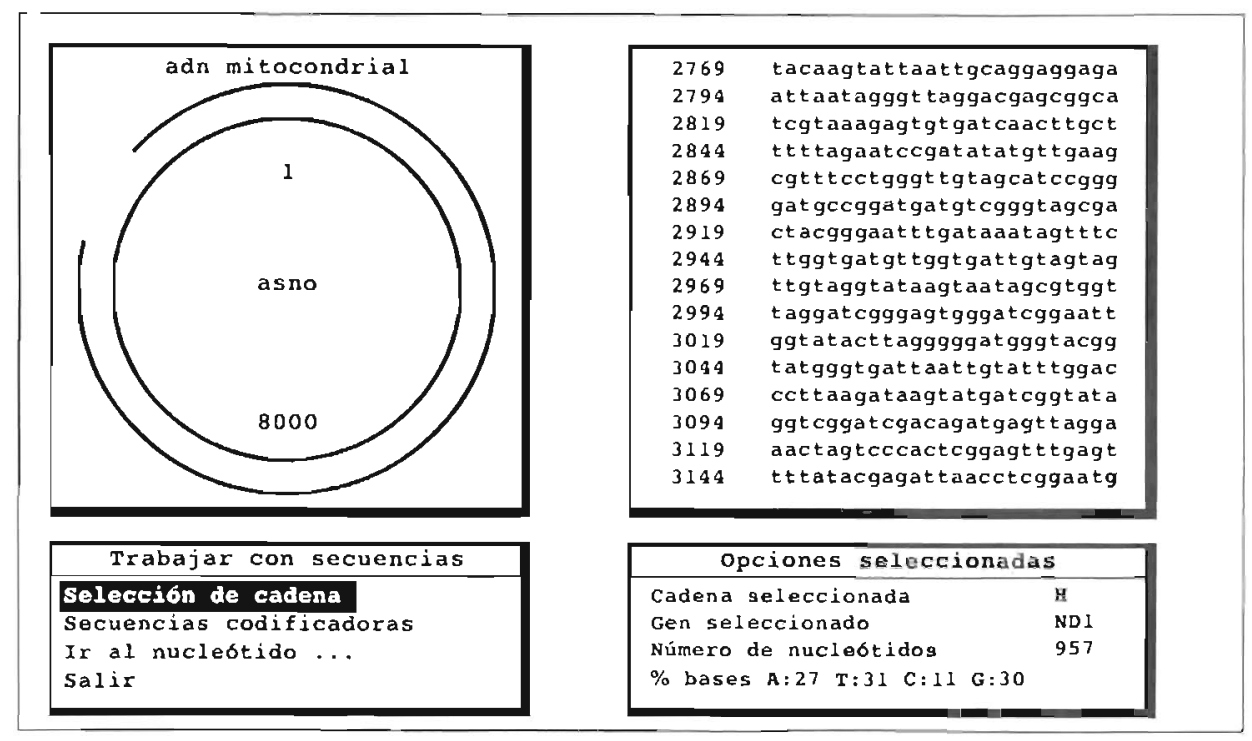

Figura 6. La pantalla muestra la ubicación espacial, la secuencia nucleotidica, la cadena del mt DNA, número de nucleótidos y porcentaje de bases nitrogenadas del gen NAD1 mitocondrial.

va (Fig. 7). También dentro de esta opción se puede realizar comparaciones de dos genes iguales o dos genes diferentes para dos especies diferentes o para la misma especie seleccionada por el usuario (Fig. 8).
La opción Técnicas Moleculares permite trabajar con las técnicas moleculares más utilizadas en la biología molecular como son el RFLP y PCR (Maniatis, F. \& Sambrook, J, 1989). Dentro de la opción RFLP, se puede

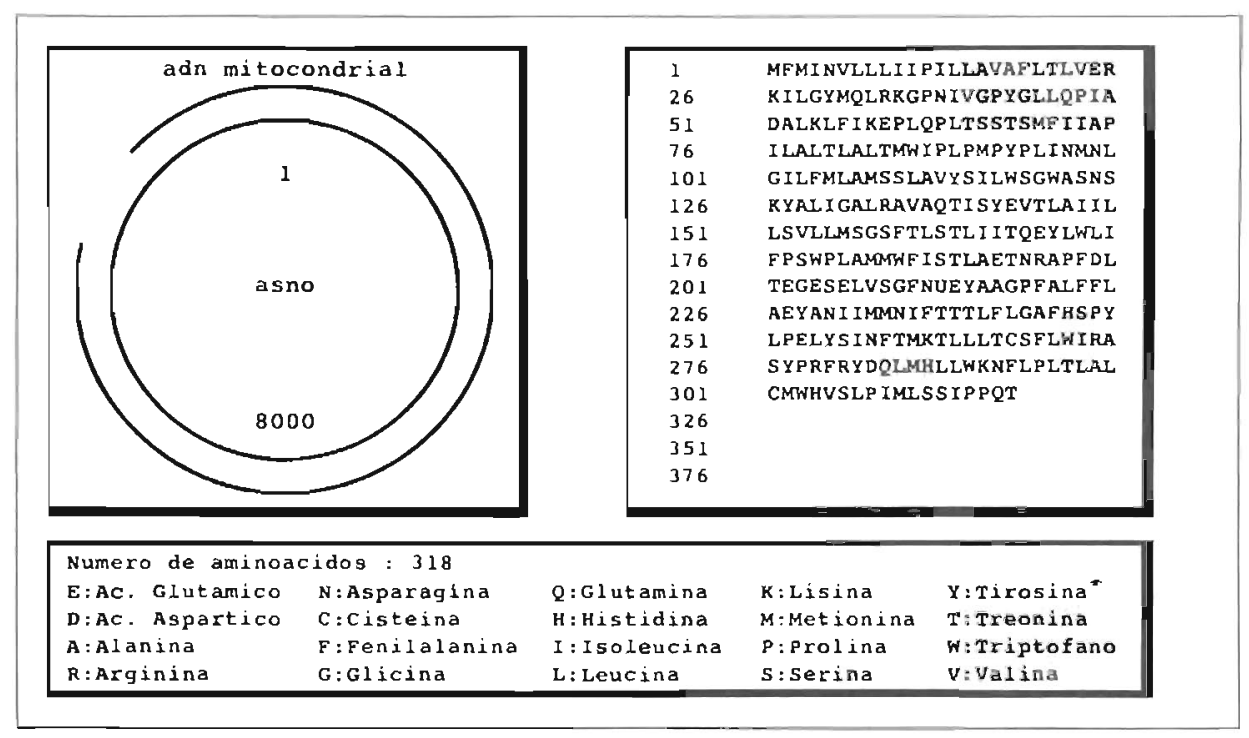

Figura 7. La pantalla muestra la secuencia de los 318 aminoácidos codificados por una sola letra del gen ND1 mitocondrial. 


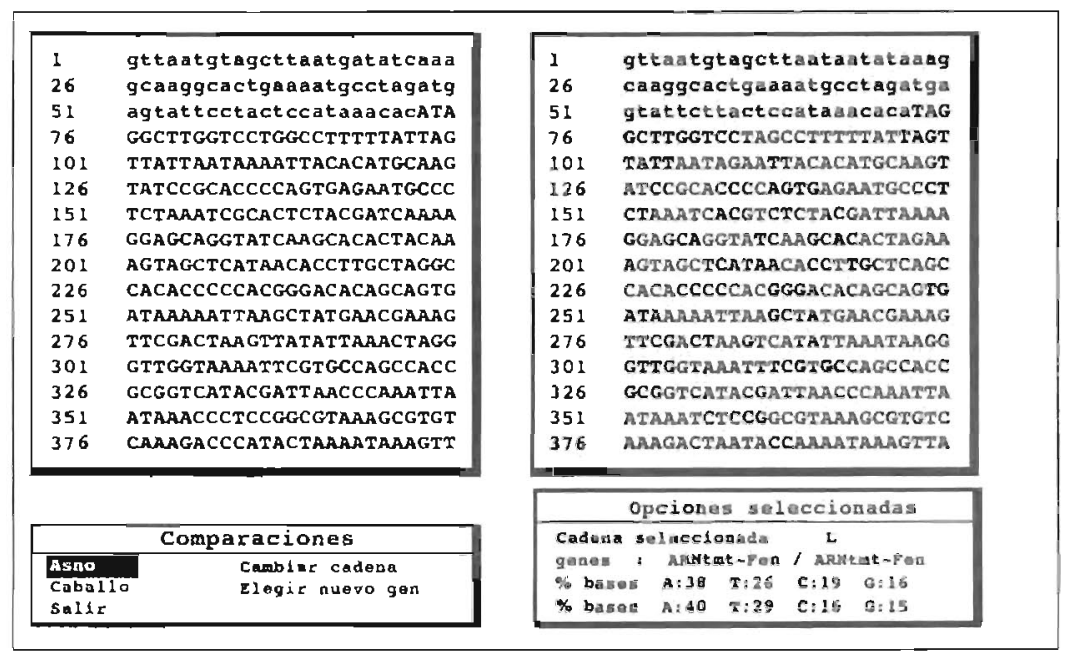

Figura 8. Las pantallas mostradas comparan la secuencia nucleotidica del tRNA-Fenilalanina mitocondrial de dos equinos (asno y caballo). Tambièn se compara los porcentajes de sus bases nitrogenadas.

seleccionar de una lista de 150 enzimas de restricción diferentes, nueve enzimas de restricción y realizar digestiones simples o dobles del mtDNA escogido (Fig. 9). De la misma manera, para la opción PCR, se puede seleccionar dos sondas o primers ya probados a nivel mundial para amplificar una secuencia específica para un mtDNA seleccionado (Fig. 10).
Para las opciones RFLP y PCR, el programa proyecta un patrón electroforético digital que permite ver al usuario los fragmentos obtenidos por RFLP o el fragmento amplificado por PCR. Además, se puede seleccionar un marcador molecular utilizado comúnmente en los laboratorios para comparar la distancia de migración de la corrida

\begin{tabular}{|lllll|}
\hline \multicolumn{4}{c}{ Selección de enzimas de restricción } & \\
\hline NaeI & NruI & SacI & SgfI & StuI \\
NarI & NsiI & SacII & SgrAI & StyI \\
NciI & PfIMI & SaII & SmaI & TagI \\
NcoI & PleI & Sau3AI & SnaI & ThaI \\
NdeI & PpuMI & Sau96I & SnaBI & Tth1IIt \\
NheI & PstI & ScaI & SpeI & TurboNaeI \\
NlaIII & PvuI & ScrFI & SphI & TrugI \\
NlaIV & PvuII & SduI & SsPI & VspI \\
NotI & RsaI & SfaNI & SstI & XbaI \\
NspI & RsrII & SfiI & SstII & XhoI \\
Adelante & Atras & salir & & \\
& & & & \\
\hline
\end{tabular}

Figura 9. Banco de datos de las enzimas de restricción utilizadas en RFLP 


\begin{tabular}{|c|c|c|c|c|}
\hline & Selección & de Sondas & Cadena L & \\
\hline I516As & L515Ba & L9388Bp & L6461Bm & L15175Bo \\
\hline L5 17 As & L6 $125 \mathrm{Ba}$ & L9 40Bp & L9337 Bm & L15289Bo \\
\hline L8912As & L6126Ba & L6464Bp & L15025Bm & L15541Bo \\
\hline L12030As & L7020Ba & L9340Bp & $\mathrm{L} 15861 \mathrm{Bm}$ & L16176Bo \\
\hline L13773As & L7907Ba & L11221Bp & $\mathrm{L} 16352 \mathrm{Bm}$ & $\mathrm{L} 514 \mathrm{Ca}$ \\
\hline L14437As & L $8786 \mathrm{Ba}$ & L15028Bp & $\mathrm{L} 48 \mathrm{Bo}$ & L8916Ca \\
\hline L14600As & L9029ва & L15791Bp & L239Bo & $\mathrm{L} 11019 \mathrm{Ca}$ \\
\hline L1 $4846 \mathrm{As}$ & $L 14616 \mathrm{Ba}$ & L1 $5864 \mathrm{BP}$ & L1 4487 Bo & $\mathrm{L} 14603 \mathrm{Ca}$ \\
\hline L15457AS & $\mathrm{L} 15672 \mathrm{Ba}$ & $\mathrm{L} 936 \mathrm{Bm}$ & L14765Bo & $\mathrm{L} 14460 \mathrm{Ca}$ \\
\hline L5 13Ba & $\mathrm{L} 16571 \mathrm{Ba}$ & L938Bm & $\mathrm{L} 14929 \mathrm{Bo}$ & $\mathrm{L} 14849 \mathrm{Ca}$ \\
\hline Adelante & Atras & Salir & & \\
\hline
\end{tabular}

Figura 10. Banco de datos de las sondas utilizadas en PCR

electroforética. Dentro de esta opción se puede obtener información molecular como son el peso molecular (en pb) y el número de los fragmentos digeridos pot RFLP (Fig. 11), o el tamaño del segmento amplificado por PCR (Fig. 12).

\section{DISCUSIÓN}

El presente reporte demuestra que con nuestro programa SISMIT Animal es posible integrar la información de la secuencia nucleotídica del DNA mitocondrial disponible en Internet de diferentes especies animales

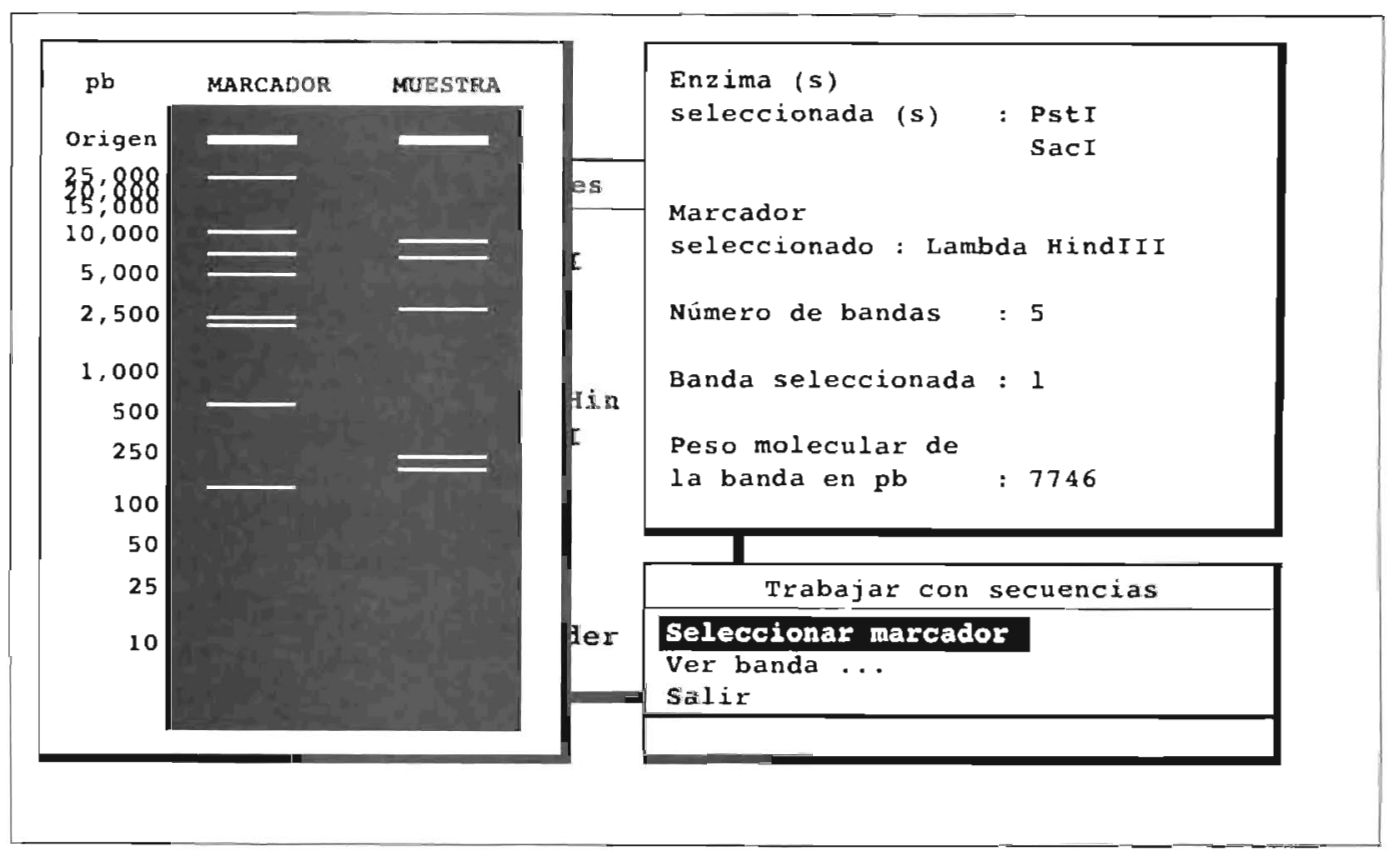

Figura 11. En la pantalla superior derecha se indica las enzimas de restricción y marcador seleccionados, y el número de bandas 


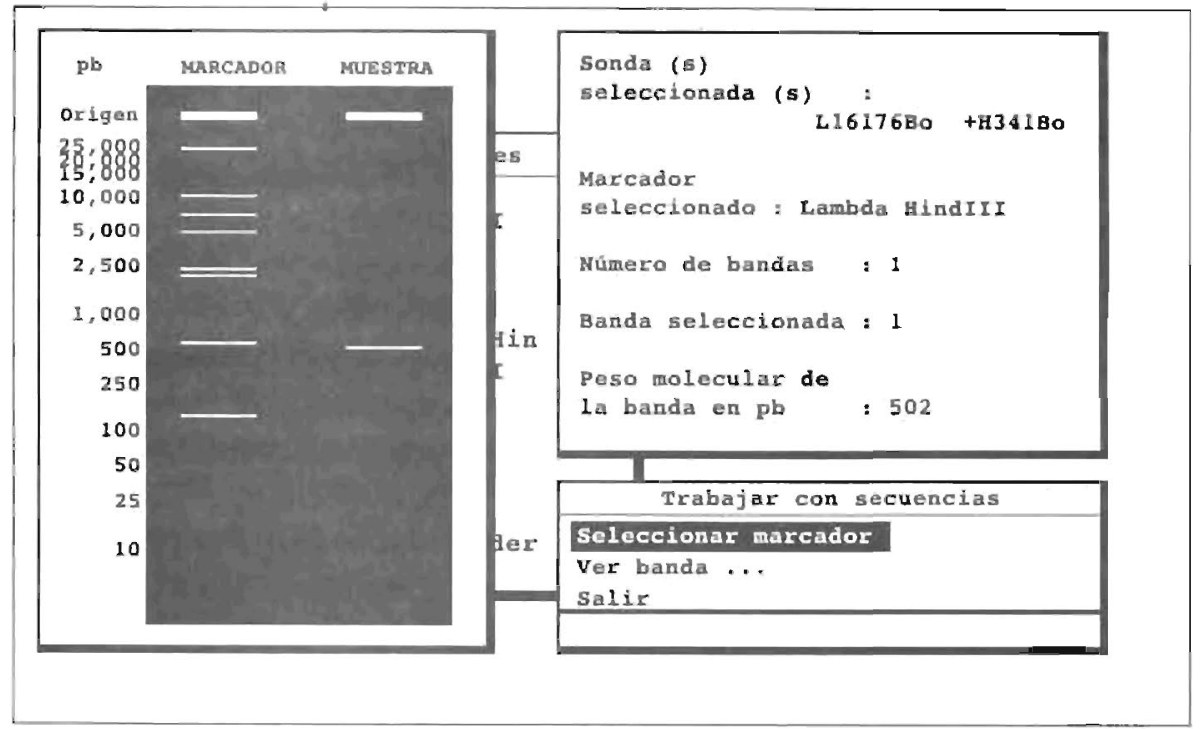

Figura 12. En la pantalla superior derecha se indica las sondas y marcador seleccionados, número de bandas, banda seleccionada y peso molecular en $\mathrm{pb}$

con la información de biología molecular utilizados en los laboratorios que analizan esta molécula. De esta manera, se pudo diseñar un programa de computación que utiliza un lenguaje informático para proyectar un sistema de análisis de imágenes y facilitar el acceso y utilización de esta información de una forma fácil, confiable y útil para los investigadores.

\section{LITERATURA CITADA}

Anderson, S., Bankier, A., Barrell, B., De Bruijn, M., Coulson, A., Drouin, J., Eperon, I., Nierlich, D., Roe, B., Sanger; F., Schreier, P., Smith, A., Staden, R. \& Young, 1. 1981. Sequence and organization of the human mitochondrial genome. Nature. 290:457-465.

Altschul, S., Gish, W., Miller, W., Myers, E. \& Lipman, D. 1990. Basic local alignment search tool. J. Mol. Biol. 215:403-410.

Bernstein, F. Koetzle, T., Williams, G. Meyer, E. Brice, M. Rodgers, J., Kennard, O, Shimanouchi, T. \& Tasumi, M. 1977. The ProteinData Bank: A computer- based archival file for macromolecular structures. J. Mol. Biol. 112: 535-542.

Brown, W., George, M. \& Wilson, M. 1979 Rapid evolution of animal mitnchondrial DNA. Proc. Natl. Sci. USA. 76(4). 1967-1971.

Brown, W. 1980. Polymorphism in mitochondrial DNA of humans as revealed by restriction endonuclease analysis. Proceeding of the National Academy of Sciences of the USA. 77: 3605-3609.

Cann, R., Stoneking, M. \& Wilson. A. 1987. Mitochondrial DNA and human evolution. Nature. 325(1): 31-36.

Genbank (INTERNET):

http://ncbinlm.nih.gov

Higuchi, R., Bowman, M., Freiberger, 0 . Ryder, O \& Wilson, A. 1984. DNA sequence from the quagga member of the horse family. Nature. 312:282-284

Karlin, S. \& Altschul, S. 1990. Methods for assessing the statistical significance of molecular sequence features by using general scoring schemes. Proc. Natl. Acad. USA. 87: 2264-2208. 
Maniatis, F. \& Sambrook, J. 1989. Molecular Cloning. A Laboratory Manual. Cold Spring Harbor Laboratory Press. 2nd. ed., New York.

Nei, M. \& Li, W. 1979. Mathematical model for studying genetic variation in terms of restriccion endonucleases. Proc. Natl. Acad. USA. 76(10): 5269-5273.

Rosamond, J. 1982. The molecular of the mitochondrion. Biochemical Journal. 202: 1-8

Scott, D., Welt, M. \& Leung, F. 1993. A computer to aid in calculating similarity in- dexes from DNA Fingerprints. Biotechniques. 14(6): 980-983.

Scotto, C. 1996. Extracción y purificación de ADN mitocondrial en vacunos criollos del Perú. Tesis para optar el título de Biólogo, UNALM, Lima, Perú.

Sismit Animal. 1999. Copyright. Sistema Mitocondrial Animal, Versión 1.0 Patente N. ${ }^{\circ}$ 0743. Indecopi. Lima, Perú.

Tenenbaum, A. \& Augenstein, M. 1981. Copyright. Estructura de datos en Pascal. Prentice-Hall Inc. 3. ed. México, D.F. 